\title{
INTERAÇÕES DISCURSIVAS EM AULAS DE QUÍMICA: CARACTERIZAÇÃO DE UM DISCURSO REFLEXIVO
}

\section{DISCURSIVE INTERACTIONS IN CHEMISTRY CLASSES: CHARACTERIZATION OF A REFLECTIVE DISCOURSE}

\author{
ARRIGO, Viviane ${ }^{1}$ \\ GIULI, Camila Marques de ${ }^{2}$ \\ BROIETTI, Fabiele Cristiane Dias $^{3}$ \\ LORENCINI JÚNIOR, Álvaro ${ }^{4}$
}

\begin{abstract}
ResUmo
Este artigo analisa as interações discursivas ocorridas entre uma estagiária de um curso de Licenciatura em Química e os alunos de uma turma do $2^{\circ}$ ano do Ensino Médio de uma escola pública. $O$ objetivo da investigação consistiu em caracterizar o discurso mediado pela estagiária no contexto de uma aula sobre Soluções Químicas. Para isso foram analisados trechos de um diálogo ocorrido durante o desenvolvimento de uma sequência de ensino pautada nos Três Momentos Pedagógicos. A análise das falas se deu com base nos pressupostos da Análise de Conteúdo e a partir da associação entre as categorias de interação propostas por Flanders e os tipos de perguntas formuladas pela estagiária. Por meio das análises realizadas, constatamos que as mediações por ela realizadas conduziram à construção de um discurso que pode ser caracterizado como reflexivo, uma vez que a estagiária explora perguntas de raciocínio, elogia e encoraja os alunos a exporem suas ideias e fornece tempo de espera para que eles elaborem suas respostas. Nesse contexto, caracterizamos o discurso como reflexivo quando a estagiária formula perguntas que possibilitam a (re)construção, negociação e compartilhamento de significados com os alunos e/ou entre os próprios alunos, bem como gerencia os processos cognitivos dos alunos dando continuidade à negociação de significados.
\end{abstract}

PaLAVRas-ChaVe: Três momentos pedagógicos; Soluções químicas; Interações discursivas.

\footnotetext{
${ }^{1}$ Universidade Estadual de Londrina (UEL) / Programa de Pós-Graduação em Ensino de Ciências e Educação Matemática (PECEM). Londrina, PR, Brasil. ORCID: http://orcid.org/0000-0002-0683-8387 e-mail: viviane_arrigo@hotmail.com

2 Universidade Estadual de Londrina (UEL) / Programa de Pós-Graduação em Ensino de Ciências e Educação Matemática (PECEM). Londrina, PR, Brasil. ORCID: https://orcid.org/0000-0002-1411-184X e-mail: cami_giuli@hotmail.com

3 Universidade Estadual de Londrina (UEL) / Programa de Pós-Graduação em Ensino de Ciências e Educação Matemática (PECEM). Londrina, PR, Brasil. ORCID: http://orcid.org/0000-0002-0638-3036 e-mail: fabieledias@uel.br

${ }^{4}$ Universidade Estadual de Londrina (UEL) / Programa de Pós-Graduação em Ensino de Ciências e Educação Matemática (PECEM). Londrina, PR, Brasil. ORCID: http://orcid.org/0000-0001-9365-2312 e-mail: Iorencinijunior@yahoo.com.br
} 
DOI: $10.12957 / \mathrm{e}-\mathrm{mosaicos} .2020 .46913$

\section{ABSTRACT}

This article analyzes the discursive interactions that took place between a chemistry undergraduate intern and students in a public high school eleventh grade class. The objective of the research was to characterize the discourse mediated by the intern in the context of a class on Chemical Solutions. For this purpose, extracts from a dialogue that took place during the development of a teaching sequence based on the Three Pedagogical Moments were analyzed. The analysis of the statements was based on the assumptions of the Content Analysis and on the association between the categories of interaction proposed by Flanders and the types of questions formulated by the trainee. Through the analyses carried out, we found that the mediations she conducted have led to the construction of a discourse that can be characterized as reflective, since the trainee explored questions of reasoning, praises and encouraged students to present their ideas and provided time for them to elaborate their answers. In this context, we characterize speech as reflexive when the trainee formulates questions that enable the (re)construction, negotiation and sharing of meanings with students and/or among students themselves, as well as managing students' cognitive processes by continuing to negotiate meanings.

Keywords: Three pedagogical moments; Chemical solutions; Discursive interactions.

\section{INTRODUÇÃO}

A Química utiliza uma linguagem específica para a representação das substâncias e transformações químicas. Por meio de símbolos, fórmulas, equações, códigos e relações matemáticas, conceitos químicos são apresentados e discutidos com os estudantes com a finalidade de inseri-los no contexto científico, contexto este que se inter-relaciona com as aplicações tecnológicas, e implicações ambientais, sociais, políticas e econômicas.

Entretanto, na maioria das vezes, os conteúdos químicos acabam sendo abordados de forma fragmentada, não contextualizada e não problematizada, no qual o conhecimento é visto como um conjunto de conceitos que devem ser acumulados na mente dos alunos, como se a aprendizagem ocorresse pelo acúmulo de informações transmitidas pelo professor ou contidas nos livros didáticos (BRASIL, 2006).

Nos documentos oficias (PCNEM, 2000; $\mathrm{PCN}^{+}, 2002$, e OCEM, 2006) para o Ensino de Química na Educação Básica é recomendado que se explicite o caráter dinâmico, multidimensional e histórico dos conhecimentos químicos por meio da utilização de abordagens contextualizadas e interdisciplinares. Quando os conteúdos químicos são abordados a partir de temas, esses ganham flexibilidade e interatividade, deslocando-se do tratamento usual de esgotar um a um cada tópico da Química para o tratamento de uma situação-problema, a qual, para ser interpretada e solucionada requer a compreensão de conceitos científicos. Trata-se do desenvolvimento de habilidades, competências e valores diante de situações reais vivenciadas pelos alunos a partir do estudo de conceitos científicos (BRASIL, 2000; BRASIL, 2002; BRASIL, 2006). 
DOI: $10.12957 /$ e-mosaicos.2020.46913

Nesse sentido, e corroborando as ideias acima mencionadas, a Base Nacional Comum Curricular para o Ensino Médio (BNCC-EM), aprovada pela Resolução no 4 de 17 de dezembro de 2018, define o conjunto orgânico e progressivo de aprendizagens essenciais que todos os alunos devem desenvolver ao longo das etapas e modalidades da Educação Básica. A BNCC apresenta uma estrutura de organização que integra a área de Ciências da Natureza e suas tecnologias (biologia, física e química) a partir de unidades temáticas: matéria e energia, vida e evolução e, terra e universo, caracterizando uma proposta interdisciplinar, que preza pelo ensino baseado em contextos reais da vida dos alunos. Além disso, preconiza o emprego de atividades investigativas, por meio do letramento científico, estimulando o protagonismo dos estudantes em sua aprendizagem e na construção de seus projetos de vida, de modo que, intervenha no mundo real com base em princípios éticos e sustentáveis (BRASIL, 2018).

À vista disso, a utilização de estratégias de ensino contextualizadas embasadas na problematização de conceitos químicos é uma forma de estimular os estudantes a construírem novos conhecimentos, a partir de situações reais vivenciadas. Conferir protagonismo aos estudantes, durante as aulas implica em criar situações interativas para que eles participem das discussões e elaboração de novos conhecimentos, seja na busca por uma solução para uma situação-problema, ou na interpretação de um fenômeno experimental. Isso requer, que o professor atue como um mediador do processo de ensino e aprendizagem, possibilitando que os alunos expressem suas ideias iniciais acerca de um assunto e as reconstruam, à medida que novas informações vão sendo inseridas na discussão durante a aula, culminando na construção de novos conhecimentos.

Desse modo, apresentamos neste estudo uma investigação realizada com uma estagiária do curso de Licenciatura em Química em suas atividades de regência, nas quais buscamos explorar situações de interações discursivas entre ela e os alunos, por meio de atividades de ensino contextualizadas, com vistas a uma formação docente inicial crítica e reflexiva. Portanto, nosso objetivo consistiu em caracterizar o discurso mediado pela estagiária no contexto de uma aula sobre Soluções Químicas.

\section{REFERENCIAL TeóRICO}

\section{O ESTUdO de SOLUÇões QuÍMICAS}

O conteúdo de Soluções Químicas é passível à contextualização, uma vez que, diariamente, misturamos componentes que resultam em uma solução, como adoçar o café, preparo de um suco em pó, o soro caseiro, entre outros. Muitos dos materiais à nossa volta são soluções, como o guaraná, que é composto principalmente por água, além de açúcar, extratos de planta e vários aditivos; a água do mar filtrada que representa uma solução de sal e muitas outras substâncias em água; o bronze, que é uma solução de cobre em zinco; até a atmosfera, que pode ser considerada uma solução gasosa gigantesca de gases, na qual o componente principal é o gás nitrogênio. Temos, portanto, a definição de solução como sendo uma mistura 
DOI: $10.12957 / \mathrm{e}-\mathrm{mosaicos} .2020 .46913$

homogênea de duas ou mais substâncias que podem ser sólidas, líquidas ou gasosas (ATKINS e JONES, 2012).

Quando usamos o termo dissolver, estamos nos referindo ao processo de produzir uma solução. Portanto, em uma solução sempre haverá um componente que estará em maior quantidade, que em geral é denominado de solvente, já as substâncias nele dissolvidas são denominadas de solutos. Assim, quando quisermos destacar o papel de uma das substâncias em relação às outras, dizemos "dissolvidas em", o que permite denominar essa última sustância como solvente. Como exemplo temos o melaço em que o açúcar está presente em quantidade superior à da água, porém esta é considerada o solvente. Normalmente o solvente determina o estado físico da solução (ATKINS e JONES, 2012).

$\mathrm{Na}$ literatura encontramos várias pesquisas a respeito das compreensões e dificuldades dos alunos quanto ao conteúdo de soluções químicas (ECHEVERRÍA, 1996; NAPPA, INSAUSTI e SIGÜENZA, 2005; CARMO, MARCONDES e MARTORANO, 2010; FERREIRA, 2015; RIBAS, BROIETTI, LEAL e PASSOS, 2017; CEDRAN, CEDRAN, ALVES e CUSTÓDIO, 2018), alguns deles explicitados a seguir.

Na investigação realizada por Nappa, Insausti e Sigüenza (2005) com alunos de 17 a 18 anos de uma escola de Ensino Médio da província de San Juan, na Argentina, foram identificados alguns obstáculos à compreensão do fenômeno da solubilidade dos materiais pelos alunos. O principal deles está relacionado a conceitos centrais e necessários para o entendimento da solubilidade das substâncias, como a definição de matéria, substância simples, substância composta e elemento químico. Além disso, dificuldades nos conceitos de polaridade e interações intermoleculares também aparecem como obstáculos à aprendizagem. Logo, não conseguem interpretar no nível microscópico a dissolução de materiais, apresentando explicações simplistas advindas de percepções sensoriais, em nível macroscópico, por exemplo, para a interação que ocorre entre as moléculas quando o açúcar é dissolvido em água.

Carmo, Marcondes e Martorano (2010) investigaram como evoluem as concepções de estudantes de Ensino Médio ( $2^{\circ}$ e $3^{\circ}$ ano) sobre o conceito de solução e do processo de dissolução. Verificou-se que, em geral, os alunos fornecem explicações macroscópicas aos conceitos, influenciados por aspectos observáveis e pelas experiências que vivenciam em seu cotidiano. Durante o ensino, as autoras conseguiram verificar uma evolução nas ideias dos alunos, que ultrapassaram a barreira do observável, quando apresentaram explicações do conceito de solução como uma mistura homogênea de substâncias, necessárias para o entendimento do processo de dissolução com maior abstração. As autoras atribuíram tais constatações à participação efetiva dos alunos na realização dos experimentos, confronto de ideias, discussões argumentativas e proposições de explicações.

Já no estudo realizado por Ribas, Broietti, Leal e Passos (2017) com licenciandos de um curso de Química foi verificado que os estudantes apresentaram dificuldades em definir corretamente os tipos de soluções de acordo com a saturação, ou seja, dificuldades em interpretar a influência da quantidade de soluto presente na solução, 
DOI: $10.12957 / \mathrm{e}-\mathrm{mosaicos} .2020 .46913$

um fator determinante para classificá-la. Nas representações elaboradas pelos estudantes, foi verificado que eles dificilmente consideram as interações entre soluto e solvente, ilustrando a solução tal como observamos a olho nu, a nível macroscópico.

Verificamos nos trabalhos mencionados que as dificuldades dos alunos no entendimento do conceito de solução, do processo de dissolução e na classificação dos sistemas advêm da atribuição de características observáveis aos sistemas. Este aspecto, muitas vezes, limita a compreensão deste conteúdo pelo fato de 0 comportamento das soluções exigirem explicações a nível microscópico. Uma solução saturada e uma insaturada, por exemplo, preparadas com a mesma quantidade de solvente, são iguais visualmente; no entanto, sabe-se que a quantidade de soluto em uma solução exerce influência sob as características do sistema, o que só pode ser interpretado com base nas interações entre as moléculas de soluto e solvente a nível atômico molecular.

Assim, para que os alunos cheguem ao entendimento do conceito de solução é preciso levá-los a refletir microscopicamente sobre a interação que ocorre entre as partículas das substâncias durante o processo de dissolução, para posteriormente identificarem características que possibilitam a classificação das soluções. Isso implica em uma ampliação, uma reconstrução das ideias iniciais por eles apresentadas sob o ponto de vista da ciência. Mortimer (1996) explica a ressignificação de ideias com base na noção de perfil conceitual, que implica na evolução de um perfil de concepções em que as novas ideias adquiridas no processo de ensino e aprendizagem passam a conviver com as ideias anteriores, de modo que cada uma delas pode ser empregada em um contexto conveniente.

No entanto, entendemos que o discurso ocorrido em sala de aula entre o professor e os alunos e entre os próprios alunos, possibilitando ressignificações conceituais, depende da forma como a aula é conduzida pelo professor, do nível de abertura que se dá para a participação dos alunos, dos tipos de perguntas que são realizadas, da maneira que são consideradas e utilizadas as ideias dos alunos, entre outros fatores. Na sequência, discutimos algumas considerações acerca da formação docente, do estágio supervisionado e sobre abordagem temática utilizada neste estudo.

\section{CONSIDERAÇÕES SOBRE A FORMAÇÃO DOCENTE}

Ao fazer uma digressão histórica sobre a formação de professores no Brasil, Gatti (2010) aponta que desde o final do século XIX, quando foi proposta a formação de docentes para o ensino das "primeiras letras" em cursos específicos com a criação das Escolas Normais, são enfrentados obstáculos no que diz respeito à formação destes profissionais. Segundo a autora, para que estes profissionais estejam aptos a lidar com as adversidades do contexto educacional, a ensinar às novas gerações conhecimentos disciplinares e valores e práticas coerentes com nossa vida civil, é necessária uma verdadeira revolução nas estruturas institucionais formativas e nos currículos da formação. 
DOI: $10.12957 /$ e-mosaicos.2020.46913

Azevedo et al. (2012) apontam que a formação de professores se tornou nos últimos 40 anos um tema presente nas discussões no cenário acadêmico brasileiro, particularmente após a criação das faculdades ou centros de formação nas universidades em 1968. Os autores discutem que durante o percurso que se inicia na formação focada no professor transmissor de conhecimentos, perpassa pelo técnico em educação, pelo educador e pesquisador, desembocando no professor pesquisadorreflexivo, as exigências da formação e o papel do professor mudaram radicalmente. Porém, ressaltam que a formação oferecida não acompanhou tais mudanças, permanecendo os cursos de licenciatura desde a sua criação sem alterações significativas em seu modelo formativo.

Em um mapeamento recentemente realizado por Assai, Broietti e Arruda (2018), os autores buscaram em periódicos da área de Ensino de Ciências pesquisas sobre a temática: estágio supervisionado na formação inicial de professores. Diante da análise de um conjunto de 87 artigos, os autores verificaram que a referida temática se desenvolveu como campo de pesquisa entre as décadas de 2008 a 2018, sendo que as publicações se intensificaram do ano de 2015 em diante, correspondendo a 46 das 87 publicações analisadas.

Tais resultados são interpretados pelos autores como fatos advindos das resoluções instituídas pelo Conselho Nacional de Educação (CNE/CP 1/2002 e CNE/CP 2/2015). As Diretrizes Curriculares Nacionais para a Formação de Professores da Educação Básica englobam um conjunto de princípios e formas de orientação inerentes à formação para a atividade docente (BRASIL, 2002; 2015). Os autores ainda destacam que apesar de haver uma preocupação por parte dos pesquisadores no que diz respeito a melhoria da formação docente, ainda existem lacunas em torno dos aspectos que regem os processos formativos, principalmente no estabelecimento da tríade formativa - professor formador/estagiário/supervisor do estágio, que pode contribuir significativamente para a superação da dicotomia entre a teoria e a prática.

A dicotomia entre a teoria e a prática ou falta de integração disciplinar é característica de um modelo de formação pautado na racionalidade técnica, que tende a separar o mundo acadêmico do mundo da prática. Tal modelo concebe e constrói o professor como um técnico, aquele que soluciona problemas por meio da aplicação de teorias e técnicas (SILVA e SCHNETZLER, 2008). Verifica-se então a necessidade de (re)pensar os processos formativos com base em uma racionalidade prática, que permita ao futuro professor, consciente e autonomamente reconhecer e assumir-se como profissional da educação, tendo condições para enfrentar criticamente os desafios do trabalho docente.

Maldaner (2013) aponta que as universidades têm tido dificuldades de superar o fosso que separa a formação pedagógica da formação específica no campo em que o futuro professor vai atuar, o que acaba criando uma sensação de vazio de saber na mente do professor. Saber os conteúdos químicos em um contexto de Química é diferente de sabê-los em um contexto de mediação pedagógica dentro do conhecimento químico. Para isso, compreendemos o Estágio Supervisionado como um momento essencial à formação de um profissional crítico e reflexivo, o qual propicia 
DOI: $10.12957 / \mathrm{e}-\mathrm{mosaicos} .2020 .46913$

experiências práticas de ensino em que os estudantes possam explorar estratégias que favoreçam a mediação pedagógica na construção dos conhecimentos.

A maneira como o professor media a troca de significados durante a construção dos conceitos caracteriza o tipo de discurso que ele promove, ao passo que, se ele utiliza as ideias dos alunos e possibilita interações que favoreçam a reflexão crítica acerca do tema em questão, ocorre o desenvolvimento cognitivo do aluno. A esse tipo de discurso Lorencini Jr (2000) denomina "discurso reflexivo". De acordo com o autor,

No processo de construção de significados acerca dos conteúdos científicos, o professor deve elaborar diferentes estratégias de ação educativa ajustadas à amplitude da diversidade de características pessoais e culturais presentes em sala de aula. Assim, se admitirmos que o processo educativo é inerente à diversidade pessoal e cultural, e que qualquer ação nesse âmbito tem que estar adaptada a esta característica, então as interações em sala de aula, em particular as argumentativas como o discurso reflexivo, devem permitir ao professor, tanto quanto possível, o reconhecimento e monitoramento dos processos cognitivos que os alunos estão desenvolvendo e realizando (LORENCINI JR., 2000, p. 58-59).

Para Vygotsky (1993), a interação, principalmente a realizada entre indivíduos face a face, é primordial no processo de internalização. Por isso, o conceito de aprendizagem mediada confere um papel privilegiado ao professor, embora seja evidente que não se adquire conhecimentos apenas com os educadores, mas sim em uma atividade conjunta nas relações colaborativas entre alunos e meio social. De um modo geral, a educação dialógico-problematizadora e a investigação-ação escolar são balizadas pelos mesmos fundamentos: diálogo e problematização (FREIRE, 1987).

Como possibilidade para estimular a participação e o envolvimento intelectual dos alunos nas discussões, tem-se a abordagem temática dos Três Momentos Pedagógicos (3MP): problematização inicial, organização do conhecimento e aplicação do conhecimento (DELIZOICOV, ANGOTTI e PERNAMBUCO, 2011). Inspirada nas ideias de Paulo Freire, esta abordagem consiste na organização de propostas de ensino a partir de temas previamente definidos e preconiza a presença da dialogicidade no desenvolvimento de cada momento.

$\mathrm{Na}$ problematização inicial, são apresentadas situações que os alunos presenciam e que estão envolvidos no tema. Os alunos são desafiados a expor o que pensam para que o professor guie a discussão e esses sintam a necessidade de aquisição de novos conhecimentos que ainda não detém. No segundo momento, organização do conhecimento, sob a orientação do professor, são trabalhados os conteúdos necessários para a solução dos problemas levantados na problematização inicial, ou seja, é guiado um estudo sistemático do conteúdo. Por fim, no terceiro momento, denominado de aplicação do conhecimento, é retomado o problema discutido na problematização inicial, a fim de solucioná-lo com base nos conceitos desenvolvidos na etapa anterior. Além disso, podem-se extrapolar os conhecimentos 
DOI: $10.12957 / \mathrm{e}-\mathrm{mosaicos} .2020 .46913$

envolvidos na questão inicial, situações diferentes da problematização inicial podem ser abordadas de forma a serem compreendidas com base nos mesmos conceitos (DELIZOICOV, ANGOTTI e PERNAMBUCO, 2011; MUENCHEN e DELIZOICOV, 2014). Na sequência, apresentamos os procedimentos metodológicos adotados nesse estudo.

\section{Encaminhamento Metodológico}

Os dados analisados nesse trabalho referem-se aos diálogos estabelecidos entre uma estagiária e os alunos durante o desenvolvimento de uma sequência de ensino que abordava o conteúdo de Soluções Químicas. A referida sequência foi elaborada pela estagiária em cooperação com a professora formadora, pois, trata-se de uma das atividades realizadas na disciplina de Estágio Supervisionado de um curso de Licenciatura em Química. A sequência de aulas abordando o conteúdo de Soluções Químicas foi organizada com base na abordagem temática dos Três Momentos Pedagógicos proposta por Delizoicov, Angotti e Pernambuco (2011) e teve duração de 6 horas/aula (300 minutos). As aulas foram desenvolvidas em uma turma do $2^{\circ}$ ano do Ensino Médio composta por 29 alunos, em uma escola pública situada no estado do Paraná.

Durante os encontros entre a estagiária e a professora formadora, discutiu-se sobre a estrutura das aulas, objetivos e possibilidades de atividades que promovessem a participação dos estudantes na construção dos conhecimentos científicos. As aulas foram gravadas em vídeo e, posteriormente, transcritas obtendo-se os registros das interações discursivas ocorridas entre a professora e os estudantes e entre os próprios estudantes.

No Quadro 1 apresentamos uma síntese das atividades desenvolvidas durante esta sequência de ensino.

Quadro 1: Síntese das atividades desenvolvidas

\begin{tabular}{|c|c|c|}
\hline $\begin{array}{l}\text { Organização das } \\
\text { aulas }\end{array}$ & Atividades & Objetivos \\
\hline $\begin{array}{l}\text { Atividade } \\
\text { Experimental } \\
\text { (Aulas } 1 \text { e 2) }\end{array}$ & $\begin{array}{l}\text { - Realização de uma atividade } \\
\text { experimental } \\
\text { envolvendo a investigativa } \\
\text { concentração de sal ( } \mathrm{NaCl} \text { - soluto) } \\
\text { em água (solvente). }\end{array}$ & $\begin{array}{l}\text { - Definir soluto, solvente e } \\
\text { solução; } \\
\text { - Classificar as soluções em } \\
\text { insaturada, saturada e } \\
\text { saturada com corpo de fundo. }\end{array}$ \\
\hline $\begin{array}{l}\text { Problematização } \\
\text { Inicial } \\
\text { (Aula 3) }\end{array}$ & $\begin{array}{l}\text { - Discussão de uma problemática } \\
\text { fictícia envolvendo o teor de } \mathrm{NaCl} \\
\text { em embalagens de soro fisiológico, } \\
\text { expresso em diferentes unidades de } \\
\text { concentração, porém, com o mesmo } \\
\text { valor numérico. (0,9 mol } / \mathrm{L}, 0,9 \mathrm{~m} / \mathrm{v} \\
\text { e } 0,9 \mathrm{~g} / \mathrm{L}) \text {, }\end{array}$ & $\begin{array}{l}\text { - Compreender as diversas } \\
\text { formas de se expressar as } \\
\text { concentrações das soluções, } \\
\text { com vistas a solucionar a } \\
\text { situação problema proposta. }\end{array}$ \\
\hline
\end{tabular}


DOI: $10.12957 / \mathrm{e}-\mathrm{mosaicos} .2020 .46913$

\begin{tabular}{|c|c|c|}
\hline $\begin{array}{l}\text { Organização do } \\
\text { Conhecimento } \\
\text { (Aulas } 4 \text { e 5) }\end{array}$ & $\begin{array}{l}\text { - Abordagem das seguintes } \\
\text { unidades de concentração: } \\
\text { concentração comum, concentração } \\
\text { em quantidade de matéria e, } \\
\text { porcentagem em massa. } \\
\text { - Resolução de uma lista de } \\
\text { exercícios sobre as unidades de } \\
\text { concentração. }\end{array}$ & $\begin{array}{l}\text { - Estabelecer relações entre as } \\
\text { unidades de concentração } \\
\text { estudadas. }\end{array}$ \\
\hline $\begin{array}{l}\text { Aplicação do } \\
\text { Conhecimento } \\
\text { (Aula 6) }\end{array}$ & $\begin{array}{l}\text { - Retomada da problematização } \\
\text { inicial; } \\
\text { - Realização de uma atividade sobre } \\
\text { os valores de concentração em } \\
\text { rótulos de produtos comerciais. }\end{array}$ & $\begin{array}{l}\text { - Interpretar os valores de } \\
\text { concentração descritos em } \\
\text { rótulos de produtos } \\
\text { comerciais. }\end{array}$ \\
\hline
\end{tabular}
Fonte: os autores.

\section{A COLETA E ANÁLISE DAS INFORMAÇÕES}

Como mencionado anteriormente, as aulas ministradas pela estagiária foram filmadas, procedimento adotado para a coleta de dados. Ao assistir às filmagens, as falas provenientes das interações entre a estagiária e os alunos foram transcritas respeitando-se a ordem cronológica de suas ocorrências durante o desenvolvimento de cada atividade da sequência de ensino. Assim, os diálogos ocorridos entre a estagiária e os alunos, obtidos pela transcrição de alguns recortes das aulas, compõem os dados analisados neste artigo. Neste artigo, as falas analisadas referem-se às discussões ocorridas durante as aulas 1 e 2 (atividade experimental) e a aula 3 (problematização inicial), às quais foram numeradas de 1 a 51 e os sujeitos envolvidos no diálogo foram codificados como: "Estagiária" e "A1, A2... A29".

A análise dos dados se deu com base nos pressupostos metodológicos da Análise de Conteúdo, um procedimento analítico que auxilia a reinterpretar as mensagens e a atingir uma compreensão de seus significados que vai além de uma descrição dos resultados (BARDIN, 2011). Esta técnica consiste em analisar as comunicações estabelecidas, a fim de ultrapassar incertezas e enriquecer a compreensão dos dados coletados. Chizzotti (2006, p. 98), afirma que "o objetivo da análise de conteúdo é compreender criticamente o sentido das comunicações, seu conteúdo manifesto ou latente, as significações explícitas ou ocultas".

Para isso, é preciso descodificar os documentos mediante inúmeros processos, que ocorrem em algumas etapas: 1. Pré-análise; 2. Exploração do material; 3. Tratamento dos resultados obtidos e interpretação.

Na pré-análise o material a ser analisado deve ser organizado por meio de leituras flutuantes, eleição dos documentos, formulação de hipóteses e elaboração de indicadores (BARDIN, 2011). Assim, diante do objetivo de caracterizar o discurso mediado pela estagiária, no contexto de uma aula sobre Soluções Químicas, selecionamos trechos das aulas em que houve interações entre a estagiária e os 
DOI: $10.12957 / \mathrm{e}-\mathrm{mosaicos} .2020 .46913$

alunos, ou seja, momentos em que há intercâmbios discursivos quando ela faz questionamentos e eles expõem suas ideias.

Durante a exploração do material, ocorre a definição das categorias, codificação das unidades de registro, que são unidades de significação, elementos unitários que visam à classificação e, das unidades de contexto, ou seja, unidade utilizada para facilitar a compreensão exata das unidades de registro, ocorre a correspondência aos limites contextuais para interpretá-la. É importante ressaltar que as categorias podem emergir durante a exploração do material e de suas unidades de contexto ou registro (categorias emergentes) ou serem previamente definidas, utilizando outro estudo como referencial para categorização (categorias a priori) (BARDIN, 2011).

Para categorizar as falas decorrentes das interações discursivas entre a estagiária e os alunos, fundamentou-se no trabalho realizado por Arrigo, Assai, Broietti e Lorencini Jr. (2018), no qual os autores utilizaram as categorias de Flanders (1970) apud Carvalho (2012) como categorias a priori para categorizar as interações entre um professor e seus alunos durante uma aula de termoquímica. Estas categorias estão descritas no Quadro 2.

Quadro 2: Categorias para análise de interações segundo Flanders.

\section{Influência Indireta:}

1. Aceitando sentimentos. Aceita e classifica os sentimentos dos estudantes de maneira não ameaçadora. Os sentimentos podem ser positivos ou negativos. Predição ou lembrança de sentimentos estão aqui incluídos.

2. Elogia ou encoraja. Elogia ou encoraja as ações ou comportamentos dos alunos. Piadas que relaxam a atenção da classe e não à custa do indivíduo em particular. Movimento de cabeça falando "am, am" ou "está certo" etc. está incluído.

3. Aceita ou usa as ideias dos alunos. Classifica, instruindo ou desenvolvendo as ideias ou sugestões dos alunos. Quando o professor introduz suas ideias, escolher a categoria 5.

4. Pergunta. Faz questões sobre o conteúdo ou procedimento, com intenção de obter respostas dos alunos.

Influência Direta:

5. Expõe. Dá falas ou opiniões sobre o conteúdo ou procedimento, expressando suas ideias, fazendo questões retóricas.

6. Dá ordens. Ordens, direções às quais é esperado que os alunos obedeçam

7. Crítica ou justifica a autoridade. Críticas, intenção de mudar o padrão de comportamento do aluno de não aceitável para aceitável, pôr o aluno para fora, explicar seus atos, extrema autorreferência. 
DOI: $10.12957 / \mathrm{e}-\mathrm{mosaicos} .2020 .46913$

8. Respondendo. Participação do aluno em resposta ao professor. O professor inicia o contato ou solicita a participação dos alunos.

9. Iniciando a participação. Participação iniciada pelo aluno. O observador precisa decidir se o aluno queria falar

10. Silêncio ou confusão. Pausa, pequenos períodos de silêncio e períodos de confusão nos quais a comunicação não pode ser entendida pelo observador.

Fonte: Adaptado de Flanders (1970) apud Carvalho (2012), p. 17.

Por conseguinte, de acordo com a divisão das interações aluno/professor, préestabelecida por Flanders e após a categorização dos diálogos, as perguntas realizadas pela estagiária foram classificadas fundamentando-se nos tipos de perguntas descritos por Carvalho (2012), sendo elas:

a) Perguntas Retóricas: aquelas que não são para os alunos responderem servem mais para uma forma de exposição do professor, ele faz a pergunta e ele mesmo responde. Não há um pequeno intervalo (mais ou menos 3 segundos) para que os estudantes possam responder, são questões do tipo: "Vocês estão entendendo?"; "Quem tem alguma pergunta?".

b) Perguntas Sem sentido: são aquelas para acalmar a consciência do professor e geralmente são feitas no final de alguma apresentação, questões como: "Preciso repetir?"; "Está claro para vocês?"; "Tudo bem, posso continuar?" Quase sempre são observados momentos de silêncio, alguns até longos, de mais de 10 segundos.

c) Perguntas de Complementaridade: são aquelas em que o professor inicia uma frase e os alunos complementam, por exemplo: "Água mole em pedra dura...?" Os alunos: "tanto bate até que fura"; O elétron é uma partícula de carga...? Os alunos: "negativa"; A aceleração da gravidade vale...? Os alunos: "9,8", e o professor completa: "metros por segundo ao quadrado, não esqueçam das unidades!". Esses questionamentos dão a impressão que toda a turma está raciocinando. Contudo, se aproximam de questões de memorização de conhecimentos específicos, reprodutíveis e não de raciocínio.

d) Perguntas com somente duas possibilidades de respostas: são aquelas em que o aluno escolherá uma resposta ou outra, sem hesitar: sim ou não, certo ou errado, quente ou frio, por exemplo: "O próton é uma partícula de carga positiva ou negativa?"; "O equilíbrio químico, nesta reação, foi deslocado para direita ou para esquerda?".

e) Perguntas que levam o aluno a raciocinar: são aquelas mais inferenciais que precisam de certo tempo para responder, para isso o aluno precisa raciocinar sobre os conteúdos que aprendeu. São um pouco mais longas seguidas de tempo para os alunos responderem. Por exemplo: "No exemplo que estou dando, como o aumento da T, 
DOI: $10.12957 /$ e-mosaicos.2020.46913

da $\mathrm{P}$ e da concentração dos reagentes, influenciam no deslocamento do equilíbrio químico dessa reação?". Nesse tipo de questão, o aluno tem que raciocinar sobre os conceitos ensinados: recordar os fatores que influenciam no deslocamento do equilíbrio químico; como influenciam; princípio de Le Chatelier e aplicar esses saberes no exemplo dado. Além do conteúdo conceitual, ele precisa dominar os conteúdos procedimentais (CARVALHO, 2012, p. 22-23; ARRIGO ASSAI, BROIETTI e LORENCINI JR., 2018, p. 52-53).

Por fim, no tratamento dos resultados obtidos e interpretação, o pesquisador retorna ao referencial teórico para embasar suas análises e para dar sentido as suas interpretações (BARDIN, 2011). Nesta etapa buscamos compreender e caracterizar o discurso estabelecido pela estagiária com base nos tipos de perguntas por ela formuladas e na forma como o diálogo foi conduzido, favorecendo ou inibindo a participação dos alunos. Em seguida, apresentamos os resultados oriundos de nosso processo analítico.

\section{RESULTADOS E DISCUSSÃo}

No Quadro 3, apresentamos um trecho do diálogo ocorrido nas aulas 1 e 2 durante a realização da atividade experimental e a categorização das falas, segundo as categorias de Flanders (Quadro 2).

Quadro 3: Diálogo entre estagiária-alunos durante a atividade experimental

\section{Diálogo estagiária-alunos}

1) Estagiária: Por que então a pessoa não afunda no mar morto? Vocês têm alguma ideia?

2) A1: Por causa da solubilidade, tem mais sal e a água e não consegue dissolver.

3) Estagiária: Então está relacionado a quantidade de sal... muito bem! $\mathrm{E}$ vocês sabem quais as características de uma solução química? A água é uma solução química?

4) A2: Não, porque uma solução precisa de dois elementos.

Categorias

C4

C8

5) Estagiária: E quais seriam esses dois elementos? Alguém sabe me dizer?

6) A2: Solvente e soluto.

7) Estagiária: Ótimo! E existe alguma relação de quantidade entre eles? Posso colocar a mesma quantidade de soluto e solvente?

8) A2: O solvente geralmente está em mais quantidade, se não vai acontecer como o mar morto e ficar acumulado.

9) Estagiária: Então, solvente e soluto se relacionam até certo ponto. Perfeito! E vocês já prepararam soluções no seu dia a dia?

10) A3: Leite com chocolate, água com café, água com açúcar, água com suco.

11) Estagiária: $E$ nessas soluções existe também uma relação de quantidade? Vamos usar o suco como exemplo.

12) A4: Sim, no suco se coloca muito fica forte ou se coloca pouco do "pózinho" fica fraco. 
DOI: $10.12957 /$ e-mosaicos.2020.46913

\section{DISCUSSÃO APÓS A REALIZAÇÃO DA ATIVIDADE EXPERIMENTAL}

13) Estagiária: Retomando pessoal... Qual então a característica de uma solução saturada com corpo de fundo?

14) A2: O sal não consegue ser dissolvido, o coeficiente de solubilidade ultrapassou.

15) Estagiária: Exato, enquanto que na saturada ela está no seu limite de solubilização. E a insaturada? $\quad$ C3, C4

16) A2: Tem menos água porque o coeficiente de solubilidade é baixo. $\quad$ C8

\begin{tabular}{|l|l} 
17) Estagiária: $E$ o que ocorreu com a rolha no item $F$ ? & C4 \\
\hline 18) & C8
\end{tabular}

18) A1: A solução ficou mais densa e a rolha subiu. $\quad$ C8

19) Estagiária: Logo, por que então a pessoa não afunda no mar morto? $\quad$ C4

20) A4: Porque o mar morto tem uma densidade maior que a nossa. $\quad$ C8 Fonte: os autores.

O diálogo a respeito da atividade experimental entre estagiária e alunos, constitui-se por um total de 20 turnos de falas, sendo 10 da estagiária e 10 dos alunos. É possível observar que todas as falas da estagiária se enquadram na categoria C4, referente a perguntas realizadas com intenção de obter respostas dos alunos e que, algumas delas foram também alocadas em outras categorias, além da C4. Já as falas dos alunos foram alocadas na categoria C8, caracterizando momentos de interação em que eles respondem as perguntas da professora estagiária.

Esta discussão possibilitou o levantamento das ideias prévias dos alunos acerca do conteúdo de Soluções Químicas, como: a existência de dois componentes em uma solução, a relação entre a quantidade de soluto e solvente, o entendimento de que o solvente se apresenta em maior quantidade a partir do exemplo do Mar Morto, exemplos de soluções preparadas em seu dia a dia, e, a utilização dos termos "forte" e "fraco" para se referir a soluções concentradas e diluídas, respectivamente.

Consideramos que a identificação dessas concepções foi possível porque a estagiária realizou perguntas com a intenção de obter respostas dos alunos, exercendo uma influência indireta no diálogo estabelecido, como explica Flanders na categoria C4. Verificamos que os alunos foram estimulados a interagir continuamente durante a aula expondo suas ideias, uma vez que, além de questioná-los, em alguns momentos, a estagiária aceitava as ideias por eles expressas para dar continuidade ao diálogo e em outros momentos, além de aceitar, ela ainda fazia elogios às respostas deles. Por isso que as falas $3,5,7,9,11$ e 15 foram alocadas em mais de uma categoria.

A fala 9, por exemplo: "Então, solvente e soluto se relacionam até um certo ponto. Perfeito! E vocês já prepararam soluções no seu dia a dia?", foi alocada nas categorias C2, C3 e C4. Verifica-se que a estagiária utiliza a palavra "perfeito!" para encorajar a resposta de $\mathrm{A} 2$ (C2), aceita a ideia de que o solvente deve estar em maior quantidade (C3) e faz uma nova pergunta (C4) sobre o preparo de soluções. Isso nos leva a inferir que a intenção da estagiária residia em manter um diálogo reflexivo com os alunos à medida que elaborava novas perguntas para os alunos pensarem e para eles proporem novas explicações para a relação entre a quantidade de soluto e 
DOI: $10.12957 / \mathrm{e}-\mathrm{mosaicos} .2020 .46913$

solvente em uma solução, entendimento necessário para explicar o fato de uma pessoa não afundar no Mar Morto.

Vale destacar também que o tempo de espera fornecido pelo professor ao realizar uma pergunta deve ser levado em consideração para classificar as perguntas por ele formuladas e caracterizar o discurso estabelecido. No estudo realizado por Arrigo, Assai, Broietti e Lorencini Jr. (2018), foi constatado que, uma pergunta que poderia ser classificada como aquela capaz de levar o aluno a raciocinar, pode se transformar em uma pergunta retórica, se não for dado o tempo necessário para os alunos responderem. Segundo os autores, isso pode comprometer o diálogo estabelecido e causar efeitos negativos para a construção do discurso reflexivo, porque há uma tendência de o próprio professor responder a pergunta, transformando-a em uma pergunta sem valor cognitivo para o raciocínio do aluno. Nessa perspectiva, o professor não fornecer tempo de espera para o aluno pensar e responder a questão em nada contribui para a construção de um discurso reflexivo, pelo contrário, não ajuda no processo de negociação de significados.

Dando continuidade à análise, foi categorizado o diálogo ocorrido entre a estagiária e os alunos durante a discussão da problematização inicial (aula 3), que envolvia a interpretação de rótulos de frascos de soro fisiológico, nos quais a concentração de cloreto de sódio $(\mathrm{NaCl})$ em solução estava expressa em diferentes unidades de concentração. Nessa atividade, os alunos deveriam interpretar os valores apresentados em cada frasco e indicar qual deles estava de acordo com a legislação (0,9g do sal a cada $100 \mathrm{~mL}$ de solução).

No Quadro 4, apresentamos a categorização das falas decorrentes dessa discussão.

Quadro 4: Diálogo entre estagiária-alunos durante a Problematização Inicial

\begin{tabular}{|c|c|}
\hline Diálogo estagiária-alunos & Categorias \\
\hline $\begin{array}{l}\text { 21) Estagiária: Como vocês disseram que conhecem } 0 \mathrm{~mol} / \mathrm{L} \text {, } \\
\text { alguém tem alguma ideia do que essa unidade expressa? }\end{array}$ & C4 \\
\hline $\begin{array}{l}\text { 22) A1: Deve ser aquela "coisinha" que a gente tava vendo que tinha } \\
\text { mol, tinha litro... um mol pra } 6,02 \times 10^{23} \ldots\end{array}$ & $\mathrm{C} 8$ \\
\hline 23) A2: Isso é moléculas. & $\mathrm{C} 8$ \\
\hline 24) A1: Mas tem a ver, porque tem também a parte do litro... & $\mathrm{C} 8$ \\
\hline 25) A2: 22,4 litros... & $\mathrm{C} 8$ \\
\hline 26) Estagiária: E o que vocês entendem por concentração? & C4 \\
\hline $\begin{array}{l}\text { 27) A8: É a porcentagem de alguma coisa, por exemplo, tem } 0,9 \\
\text { concentrado em } 100 \mathrm{~mL} \text { de solução. }\end{array}$ & $\mathrm{C} 8$ \\
\hline $\begin{array}{l}\text { 28) Estagiária: Então vocês acham que concentração é a quantidade } \\
\text { de uma substância em uma solução? Mais ou menos isso? Todos concordam } \\
\text { com } A 8 \text { ? }\end{array}$ & C3; C4 \\
\hline 29) Alunos: Sim! & C8 \\
\hline $\begin{array}{l}\text { 30) Estagiária: É justamente isso. Quando vamos preparar um suco, } \\
\text { por exemplo, podemos fazer um suco muito, ou pouco concentrado. E essa } \\
\text { concentração pode ser expressa de maneiras diferentes, concentração comum, } \\
\text { em quantidade de matéria e em título ou porcentagem. Agora, avaliando os } \\
\text { rótulos, o que cada uma das unidades representa? Esse } \% \text {, o que ele representa? }\end{array}$ & C3; C4 \\
\hline
\end{tabular}


DOI: $10.12957 / \mathrm{e}-\mathrm{mosaicos} .2020 .46913$

\begin{tabular}{|c|c|}
\hline $\begin{array}{l}\text { 31) A3: Mas tá falando que tem } 0,9 \mathrm{~g} \text { em } 100 \mathrm{~mL} \text {, só que o frasco tem } \\
250 \mathrm{~mL} . . .\end{array}$ & $\mathrm{C} 8$ \\
\hline $\begin{array}{l}\text { 32) Estagiária: Então, observem o que o } A 3 \text { disse, no frasco de } \\
250 \mathrm{~mL} \text { terá mais ou menos cloreto? }\end{array}$ & $\mathrm{C} 3 ; \mathrm{C} 4$ \\
\hline 33) Alunos: Mais!!!!!! & $\mathrm{C} 8$ \\
\hline 34) A2: Terá $2,25 \mathrm{~g}$ de cloreto. & $\mathrm{C} 8$ \\
\hline 35) A4: Acho que tem $0,9 \mathrm{~g}$ em $250 \mathrm{~mL}$. & $\mathrm{C} 8$ \\
\hline $\begin{array}{l}\text { 36) Estagiária: Mas voltando a problemática, qual vocês acham que } \\
\text { está de acordo com a legislação? }\end{array}$ & $\mathrm{C} 4$ \\
\hline 37) A10: O último... & $\mathrm{C} 8$ \\
\hline 38) A11: O segundo... & $\mathrm{C} 8$ \\
\hline 39) A12: O primeiro ou segundo... & $\mathrm{C} 8$ \\
\hline 40) A13: Professora é o segundo, não é? & $\mathrm{C} 8$ \\
\hline $\begin{array}{l}\text { 41) A5: A última porque o mol é mais fácil de ser equivalente com o } \\
\text { litro. }\end{array}$ & $\mathrm{C} 8$ \\
\hline $\begin{array}{l}\text { 42) A9: A última porque o mol é moléculas e cada molécula tem um } \\
\text { percentual. }\end{array}$ & $\mathrm{C} 8$ \\
\hline $\begin{array}{l}\text { 43) A6: Eu acho que é a primeira, porque esse } 0,9 \mathrm{~g} \text { não é uma } \\
\text { substância exata, que tem que fazer a porcentagem desse valor, daí esse } 0,9 \\
\text { tá em } 100 \text {. }\end{array}$ & $\mathrm{C} 8$ \\
\hline 44) Estagiária: Não. Então o primeiro não, descartado. E o segundo? & $\mathrm{C} 3, \mathrm{C} 4$ \\
\hline $\begin{array}{l}\text { 45) A2: Da menos não é? Vai ficar } 0,09 \mathrm{~g} \text { para } 100 \mathrm{~mL} \text { não é? Ou } 0,9 \mathrm{~g} \\
\text { em um litro. }\end{array}$ & $\mathrm{C} 8$ \\
\hline $\begin{array}{l}\text { 46) Estagiária: E o terceiro? } 0,9 \mathrm{~mol} / \mathrm{L}, \text { o que será que envolve esse } \\
\text { mol? Moléculas? Vamos ver, respondam aí para mim. }\end{array}$ & $\mathrm{C} 4$ \\
\hline 47) A2: Mol é da massa da tabela periódica. & C8 \\
\hline \multicolumn{2}{|c|}{10 MINUTOS PARA DISCUSSÃO E ELABORAÇÃO DE UMA EXPLICAÇÃO } \\
\hline $\begin{array}{l}\text { 48) Estagiária: Pessoal, voltando então para os frascos. Como } \\
\text { interpretar o terceiro? }\end{array}$ & $\mathrm{C} 4$ \\
\hline 49) A2: Mol é da massa da tabela periódica. & $\mathrm{C} 8$ \\
\hline $\begin{array}{l}\text { 50) Estagiária: Observem, como precisamos utilizar a massa molar } \\
\text { da tabela, quando convertemos o mol/L em } \mathrm{g} / \mathrm{L} \text {, chegamos a } 52,65 \mathrm{~g} / \mathrm{L} \text { na } \\
\text { solução 3. Comparada a solução de } 0,9 \mathrm{~g} / \mathrm{L} \text {, isso é muito ou é pouco? }\end{array}$ & $\mathrm{C} 3, \mathrm{C} 4$ \\
\hline 51) A1: Muito! & $\mathrm{C} 8$ \\
\hline 52) A2: Nesse aí tem bastante. & $\mathrm{C} 8$ \\
\hline $\begin{array}{l}\text { 53) Estagiária: Estão vendo como o mol engana!? } 0,9 \mathrm{~mol} / \mathrm{L} \text { não é } \\
\text { o mesmo que } 0,9 \mathrm{~g} / \mathrm{L} \text {, é preciso utilizar a massa molar para converter. Mas e } \\
\text { a porcentagem? Qual volume está relacionado a porcentagem? Precisamos } \\
\text { compreender essa unidade. }\end{array}$ & $\mathrm{C} 3 ; \mathrm{C} 4$ \\
\hline 54) A4: $100 \mathrm{~mL} .0,9 \mathrm{~g} \mathrm{em} 100$ & $\mathrm{C} 8$ \\
\hline $\begin{array}{l}\text { 55) Estagiária: Então vocês acham que } 0,9 \mathrm{~g} \text { está relacionado a } \\
100 \% \text { de alguma coisa? }\end{array}$ & C3; C4 \\
\hline $\begin{array}{l}\text { 56) A7: Eu acho que é a primeira, porque } 0,9 \mathrm{~g} \text { tá em } 100 \text {, e em } 250 \\
\text { tem mais. }\end{array}$ & $\mathrm{C} 8$ \\
\hline 57) A3: O primeiro, por que tá por cento. $0,9 \mathrm{~g}$ em $100 \mathrm{~mL}$. & $\mathrm{C} 8$ \\
\hline
\end{tabular}


DOI: $10.12957 / \mathrm{e}-\mathrm{mosaicos} .2020 .46913$

Nesse quadro, mostramos um diálogo que se constitui por um total de 37 falas, sendo 12 da estagiária e 25 dos alunos. Podemos observar que assim como no trecho anteriormente analisado, todas as falas da estagiária se enquadram na categoria C4 e que algumas delas foram alocadas em outras categorias, além dessa. As falas dos alunos também foram alocadas na categoria $\mathrm{C8}$, referente a participação em resposta aos questionamentos do professor. O diálogo possibilitou identificar algumas ideias prévias dos alunos como: a relação da unidade $\mathrm{mol} / \mathrm{L}$ com o volume molar dos gases em condições normais de temperatura e pressão, a relação entre a quantidade de soluto e o volume total do frasco, e, a associação da porcentagem a um volume de $100 \mathrm{~mL}$ de solução. Por mais que essas ideias sejam provenientes de concepções de senso comum, é perceptível a tentativa dos alunos de solucionar o problema apresentado, assim como é notória a frequência com que eles participam da discussão, o que nos indica que a estagiária conseguiu criar um espaço de interação e reflexão durante as aulas.

Verifica-se novamente que algumas perguntas da estagiária foram alocadas em mais de uma categoria, como é o caso da fala 32: "Então, observem o que o A3 disse, no frasco de 250mL terá mais ou menos cloreto?" que está classificada na C3 e C4, pois, além de questionar ela aceita a ideia expressa por A3 no turno que antecede. Outras falas foram alocadas somente na categoria $\mathrm{C} 4$, momentos em que percebemos que a estagiária questiona, porém não utiliza as ideias dos alunos, como na fala 46: "E o terceiro? 0,9mol/L, o que será que envolve esse mol? Moléculas? Vamos ver, respondam aí para mim", em que ela guia a discussão para que eles pensem no que está representado no rótulo do frasco número 3.

Situações semelhantes ocorreram nas falas 21, 26, 36, 46, 48, uma frequência significativa em relação ao total deste trecho de 12 falas da estagiária. Apesar de a estagiária ter fornecido o tempo de espera necessário para que os alunos respondessem, entendemos que tais situações podem limitar a construção de um discurso reflexivo, pois, mesmo que as perguntas apresentem valor cognitivo para o raciocínio dos alunos, não considerar as ideias por eles expressas pode inibi-los em discussões posteriores.

Observa-se também no intervalo de falas entre os turnos 37 a 43 que os alunos estão discutindo qual dos frascos apresenta o valor da concentração segundo a legislação e em seguida, na fala 44, a estagiária menciona que o primeiro frasco não é e guia a discussão para a interpretação do valor do segundo frasco. Segundo Lorencini Jr. (2019) o discurso reflexivo caracteriza-se pelas habilidades do professor em formular perguntas que possibilitem a construção, atribuição, negociação e compartilhamento de significados com os alunos e/ou entre os próprios alunos, bem como de gerenciar os processos cognitivos dos alunos dando continuidade à negociação de significados. Logo, entendemos que, em momentos como esse, a estagiária não potencializou a negociação de significados, o que nos leva a inferir que ela demonstrou algumas limitações com relação a construção de um discurso reflexivo. 
DOI: $10.12957 /$ e-mosaicos.2020.46913

Na sequência, para compreendermos a caracterização do discurso da estagiária, distribuímos as 57 falas dos trechos analisados nas categorias de Flanders e nos tipos de perguntas descritos por Carvalho (2012), originando o Quadro 5.

Quadro 5: Categorização das interações discursivas entre estagiária-alunos e os tipos de perguntas

\begin{tabular}{|c|c|c|c|c|c|c|}
\hline \multicolumn{2}{|c|}{$\begin{array}{l}\text { Categorização de } \\
\text { interação verbal } \\
\text { estagiária-aluno }\end{array}$} & \multicolumn{5}{|c|}{ Tipos de perguntas } \\
\hline Categoria & $\begin{array}{l}\mathbf{N} . \\
\text { de } \\
\text { falas }\end{array}$ & Retórica & $\begin{array}{l}\text { Sem } \\
\text { sentido }\end{array}$ & Complementaridade & $\begin{array}{l}\text { Duas } \\
\text { possibilidades } \\
\text { de resposta }\end{array}$ & Raciocínio \\
\hline $\begin{array}{l}\text { 1.Aceitando } \\
\text { sentimentos }\end{array}$ & - & - & - & & 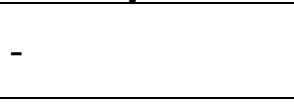 & - \\
\hline $\begin{array}{l}\text { 2.Elogio ou } \\
\text { encorajamento }\end{array}$ & 3 & - & - & & - & $(3),(7),(9)$ \\
\hline $\begin{array}{l}\text { 3.Aceitando } \\
\text { ideias }\end{array}$ & 13 & & - & & $\begin{array}{l}(11),(28),(32), \\
(50),\end{array}$ & $\begin{array}{ll}(3), & (5), \\
(7), & (9), \\
(15), & (30), \\
(44), & (53), \\
(55) & \end{array}$ \\
\hline 4.Perguntando & 22 & - & - & - & $\begin{array}{l}(11),(28),(32), \\
(50),\end{array}$ & 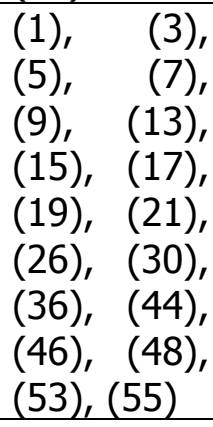 \\
\hline 5. Exposição & - & & - & - & - & - \\
\hline $\begin{array}{l}\text { 6.Dando } \\
\text { direções }\end{array}$ & - & & - & - & - & - \\
\hline 7.Criticando & - & & - & - & - & - \\
\hline $\begin{array}{ll}8 . & \text { Alunos } \\
\text { respondendo }\end{array}$ & 35 & & & & & \\
\hline $\begin{array}{l}\text { 9.Alunos } \\
\text { iniciando a } \\
\text { fala }\end{array}$ & - & & & & & \\
\hline 10.Silêncio & - & & & & & \\
\hline
\end{tabular}

Fonte: os autores.

No Quadro 5, que trata da categorização das interações discursivas entre estagiárias e alunos associadas aos tipos de perguntas, além da alocação das falas entre os envolvidos nas categorias de Flanders, observa-se a classificação das perguntas realizadas pela estagiária, de acordo com os tipos de pergunta descritos por Carvalho (2012). Do total de 57 falas que compõem os dois trechos do diálogo, 22 são 
DOI: $10.12957 / \mathrm{e}-\mathrm{mosaicos} .2020 .46913$

da estagiária, sendo que 18 foram classificadas como perguntas de raciocínio e 4 como perguntas com duas possibilidades de resposta. Nas categorias 2 (elogio ou encorajamento) e 3 (aceitando ideias) observa-se também a alocação de falas da estagiária, o que ocorreu pelo fato de algumas perguntas apresentarem conteúdo referente a mais de uma categoria, como discutido anteriormente.

Logo, as 13 falas alocadas na categoria 3 e as 3 alocadas na categoria 2 fazem parte das 22 perguntas realizadas ao longo do diálogo. Por exemplo, a fala 53: "Estão vendo como o mol engana!? 0,9 mol/L não é o mesmo que 0,9 $\mathrm{g} / \mathrm{L}$, é preciso utilizar a massa molar para converter. Mas e a porcentagem? Qual volume está relacionado a porcentagem? Precisamos compreender essa unidade", está alocada nas categorias 3 e 4, pois foi interpretada como uma pergunta de raciocínio em que a estagiária aceita as ideias de $A 1$ e $A 2$ quando eles comparam as unidades $\mathrm{g} / \mathrm{L} \mathrm{e} \mathrm{mol} / \mathrm{L}$ e, em seguida orienta o diálogo para que os alunos pensem a respeito da concentração expressa em quantidade de matéria.

Verifica-se que, das 18 falas classificadas como perguntas de raciocínio, 3 (3, 7 , e 9) foram alocadas nas categorias C2, C3 e C4; enquanto que $6(5,15,30,44,53$ e 55) foram alocadas nas categorias C3 e C4 e, finalmente $9(1,13,17,19,21,26$, 36,46 e 48) foram alocadas somente na categoria C4. Com relação as 4 perguntas classificadas como aquelas com duas possibilidades de resposta, todas $(11,28,32$ e 50) foram alocadas nas categorias C3 e C4.

Compreendemos que o fato de a maioria das perguntas serem de raciocínio, elas conferem indícios de que a estagiária tentou construir um discurso reflexivo, pois implica na formulação de perguntas com alto valor cognitivo que oportunizam aos alunos refletirem acerca do conteúdo e das ideias que vão surgindo durante a discussão, no sentido de (re)construir novas ideias em consonância com o conhecimento científico. Logo, constatamos que, na maioria das vezes, a estagiária manteve um discurso que favoreceu o diálogo entre os sujeitos, por meio do qual ela fazia perguntas, os alunos respondiam e ela dava um feedback positivo, seja elogiando e/ou encorajando-os a continuarem elaborando suas ideias e/ou formulando uma nova pergunta com base nas respostas fornecidas, dando continuidade as interações discursivas.

Com relação às perguntas com duas possibilidades de resposta, mesmo que elas não tenham o mesmo valor cognitivo para o raciocínio do aluno, verifica-se que elas levaram os alunos a pensarem, como no caso da fala 32: "Então observem o que o A3 disse, no frasco de $250 \mathrm{~mL}$ terá mais ou menos cloreto?" Observa-se que a estagiária utilizou a ideia de A3 para formular uma nova pergunta, que apesar de possibilitar apenas as respostas "mais ou menos", levou os alunos a refletirem sobre a quantidade de sal em relação ao volume total do frasco, como percebe-se nas falas 33, 34 e 35: Alunos: Mais!!!!!!; A2: "Terá 2,25g de cloreto"; A4: "Acho que tem 0,9g em 250mL".

Além disso, Lorencini Jr. (2019) aponta que, quando o professor utiliza perguntas retóricas, busca encadear seu próprio discurso, ou seja, guia-lo e não com 
o objetivo central de que os alunos respondam. Portanto, constatamos que a estagiária conduziu o discurso na intenção de que os alunos respondessem as perguntas, expusessem suas ideias e discutissem entre si na busca por explicações para os questionamentos propostos. Tais resultados indicam que o diálogo estabelecido entre a estagiária e os alunos e entre os próprios alunos foi guiado no sentido de dar oportunidades para reflexões sobre os problemas envolvendo a classificação das soluções na atividade experimental e a solução do problema sobre a concentração de $\mathrm{NaCl}$ no soro fisiológico.

No entanto, entendemos que o fato de algumas perguntas terem sido alocadas apenas na categoria C4 pode ter limitado a construção de um discurso reflexivo, pois, mesmo que essas tenham sido classificadas como perguntas de raciocínio, percebemos que em algumas dessas situações a estagiária não utilizou as ideias dos alunos para orientar o diálogo em busca de uma solução para o questionamento proposto. Nas falas 45 e 46 observa-se tal ocorrência: A2: "Dá menos não é? Vai ficar 0,09g para $100 \mathrm{~mL}$ não é? Ou 0,9g em um litro; Estagiária: E o terceiro? 0,9mol/L, o que será que envolve esse mol? Moléculas? Vamos ver, respondam aí para mim". Verifica-se que A2 respondeu ao questionamento anterior como em outros questionamentos, demonstrando dificuldades na compreensão da relação soluto/solução, porém, a estagiária não considerou tais dúvidas, priorizando a discussão no sentido da interpretação dos valores de concentração apresentados em cada frasco.

Nesse caso, compreendemos que apesar de haver interação entre os sujeitos, o discurso torna-se menos dialógico, ao passo que a estagiária acaba não utilizando as ideias dos alunos. Isso, portanto, limita a sua caracterização como um discurso reflexivo, uma vez que, o professor acaba por explorar de forma tímida o processo cognitivo do aluno (MORTIMER e SCOTT, 2002). Entretanto, ao compararmos os resultados encontrados neste trabalho com os resultados da investigação realizada por Arrigo, Assai, Broietti e Lorencini Jr. (2018), constatamos que o padrão do discurso construído pela estagiária pode ser caracterizado em sua maioria como reflexivo, pois, foram exploradas perguntas de raciocínio, houve momentos em que os alunos foram elogiados e encorajados a expor suas ideias e foi dado o tempo necessário para a elaboração de respostas pelos alunos. Além disso, observamos nos diálogos que a estagiária explorou o processo cognitivo dos alunos com diferentes tipos de perguntas que possibilitaram o estabelecimento de relações conceituais com o conteúdo estudado, dando continuidade ao processo de construção de novas ideias por parte dos alunos.

Sendo assim, concluímos que o discurso reflexivo, constituído por perguntas consistentes propostas pela estagiária, foram capazes de reestruturar as concepções prévias dos alunos, levando-os a construir novos significados acerca do conteúdo de soluções químicas. Voltando-nos para a formação inicial da estagiária, podemos inferir que esta atividade, desenvolvida como componente curricular do Estágio Supervisionado contribuiu de maneira expressiva para a aprendizagem docente da futura professora, uma vez que, estas experiências também a levaram a refletir e se reestruturar continuamente para atender às demandas cognitivas dos alunos. 
DOI: $10.12957 / \mathrm{e}-\mathrm{mosaicos} .2020 .46913$

\section{CONSIDERAÇÕES FINAIS}

Diante do objetivo proposto para esta investigação, ou seja: caracterizar o discurso mediado pela estagiária, no contexto de uma aula sobre Soluções Químicas, constatamos que a estagiária buscou estabelecer um discurso reflexivo durante as discussões da atividade experimental e da problemática sobre o teor de $\mathrm{NaCl}$ em soro fisiológico. Esse processo foi marcado pela reformulação das concepções prévias dos alunos, assim como no desenvolvimento profissional da estagiária. Os questionamentos propostos pela estagiária foram capazes de gerar conflitos a serem resolvidos pelos alunos, que buscaram propor soluções para os mesmos mediante um processo de reflexão conjunta.

Além disso, percebemos que a utilização de uma problemática relacionada ao cotidiano dos alunos contribuiu para o estabelecimento desse tipo de discurso, uma vez que as ideias prévias identificadas durante a análise são provenientes de uma tentativa dos alunos de solucionar os problemas apresentados, bem como de responder as questões que forem emergindo do diálogo estabelecido.

Tais constatações se devem ao fato que a estagiária estabeleceu um diálogo que explorou o processo cognitivo dos alunos com diferentes tipos de perguntas, que possibilitaram o estabelecimento de relações conceituais com o conteúdo estudado, dando continuidade ao processo de construção de novas ideias, uma vez que, os alunos buscavam elaborar respostas para os questionamentos por ela realizados porque se tratavam de perguntas formuladas com base nas ideias por eles expressas. Além disso, ela os elogiava e os encorajava, fornecendo o tempo necessário para que eles pensassem e expusessem suas ideias. Esse tipo de discurso mantém-se como uma contínua construção e (re)construção de ideias, guiados pelos tipos de perguntas elaboradas pela estagiária que caracterizou o discurso por ela estabelecido como reflexivo na maioria das vezes, permitindo a eles a construção de novas ideias, embasadas cientificamente.

Nesse contexto investigativo, consideramos que a utilização dos Três Momentos Pedagógicos como uma metodologia de organização do ensino, bem com as atividades propostas pela estagiária para conduzir a aula. Tais atividades apresentaram-se promissoras no que tange ao estabelecimento de um discurso de caráter reflexivo, uma vez que, as intervenções da estagiária foram na maioria das vezes desencadeadas pelas respostas e retornos dos alunos.

\section{REFERÊNCIAS}

ARRIGO, V.; ASSAI, N. D. S.; BROIETTI, F. C. D.; LORENCINI, JR., Á. Análise das interações verbais professor-aluno: implicações para a construção de um discurso reflexivo. Amazônia - Revista de Educação em Ciências e Matemáticas, v. 14, n. 32, p. 48-60, 2018. 
DOI: $10.12957 / \mathrm{e}-\mathrm{mosaicos} .2020 .46913$

AZEVEDO, R. O. M.; GHEDIN, E.; SILVA-FORSBERG, M. C.; GONZAGA, A. M. Formação inicial de professores da educação básica no Brasil: trajetória e perspectivas. Revista Diálogo Educacional, v. 12, n. 37, p. 997-1026, 2012.

ASSAI, N. D. S.; BROIETTI, F. C. D.; ARRUDA, S. M. O estágio supervisionado na formação inicial de professores: estado da arte das pesquisas nacionais da área de ensino de ciências. Educação em Revista, v. 34, p. 1-44, 2018.

ATKINS, P.; JONES, L. Princípios de Química: questionando a vida moderna e o meio ambiente. 5. ed. Porto Alegre: Bookman, 2012.

BARDIN, L. Análise de conteúdo. São Paulo: Edições 70, 2011.

BRASIL. Base Nacional Comum Curricular: educação é a base. Ensino Médio. Brasília: MEC, 2018. Disponível em: http://basenacionalcomum.mec.gov.br/abase/\#medio. Acesso em 18 dez. 2019.

BRASIL. Conselho Nacional de Educação. Diretrizes Curriculares Nacionais para a Formação de Professores da Educação Básica, em nível superior, curso de licenciatura, de graduação plena. Parecer CNE/CP n. 9/2001, de 20 de maio de 2001.

Brasília. Diário Oficial da República Federativa do Brasil, 18 de janeiro de 2002, Seção 1, p. 4.

BRASIL. Conselho Nacional de Educação. Define as Diretrizes Curriculares Nacionais para a formação inicial em nível superior (cursos de licenciatura, cursos de formação pedagógica para graduados e cursos de segunda licenciatura) e para a formação continuada. Resolução CNE/CP n. 02/2015, de $1^{0}$ de julho de 2015. Brasília, Diário Oficial da República Federativa do Brasil, seção 1, n. 124, p. 8-12, 02 de julho de 2015.

BRASIL. Ministério da Educação (MEC), Secretaria de Educação Média e Tecnológica (Semtec). Parâmetros Curriculares Nacionais para o Ensino Médio. Brasília: MEC/Semtec, 2000.

BRASIL. Ministério da Educação (MEC), Secretaria de Educação Média e Tecnológica (Semtec). PCN+ Ensino Médio: orientações educacionais complementares aos Parâmetros Curriculares Nacionais - Ciências da Natureza, Matemática e suas Tecnologias. Brasília: MEC/Semtec, 2002.

BRASIL. Ministério da Educação (MEC), Secretaria de Educação Básica. Orientações Curriculares para o Ensino Médio. Brasília: MEC, 2006.

CARMO, M. P.; MARCONDES, M. E. R.; MARTORANO, S. A. A. Uma interpretação da evolução conceitual dos estudantes sobre o conceito de solução e processo de 
DOI: $10.12957 / \mathrm{e}-\mathrm{mosaicos} .2020 .46913$

dissolução. Revista Electrónica de Enseñanza de las Ciencias, v. 9, n. 1, p. 35-52, 2010.

CARVALHO, A. M. P. Os Estágios nos Cursos de Licenciatura. São Paulo: Cengage Learning, 2012.

CEDRAN, D. P.; CEDRAN, J. C.; ALVES, M. C.; CUSTÓDIO, M.D. Os três aspectos do conhecimento químico: desenvolvendo relações sobre o tema soluções. Kiri-Kerê: Pesquisa em Ensino, n. 5, 2018.

CHIZZOTTI, A. Pesquisa em ciências humanas e sociais. São Paulo: Cortez, $8^{a}$ ed., 2006.

DELIZOICOV, D.; ANGOTTI, J. A.; PERNAMBUCO, M. M. Ensino de Ciências: fundamentos e métodos. 4 ed. São Paulo: Cortez, 2011.

ECHEVERRÍA, A. R. Como os estudantes concebem a formação de soluções. Química Nova na Escola, n.3, 1996.

FREIRE, P. Pedagogia do oprimido. 17 ed. Rio de Janeiro: Paz e Terra, 1987.

FERREIRA, J. A. M. G. (2015). Dificuldades de aprendizagem do conteúdo de soluções: proposta de ensino contextualizada. 2015. (Tese de Doutorado, Universidade Federal do Rio Grande do Norte - UFRN, Natal-RN).

GATTI, B. A. Formação de professores no Brasil: características e problemas. Educação \& Sociedade, v. 31, n. 113, p. 1355-1379, 2010.

LORENCINI JR., Á. Ensino por perguntas: interações discursivas e construção de significados. 1 ed. Curitiba: Appris, 2019.

LORENCINI JR., Á. (2000). O professor e as perguntas na construção do discurso em sala de aula. 2000. (Tese de Doutorado, Faculdade de Educação, Universidade de São Paulo - USP, Brasil).

MALDANER, O. A. A formação inicial e continuada de professores de química: professor/pesquisador. 4 ed. Ijuí: Editora Unijuí, 2013.

MORTIMER, E. F. Construtivismo, mudança conceitual e ensino de ciências: para onde vamos? Investigações em Ensino de Ciências, v. 1, n. 1, p. 20-39, 1996.

MORTIMER, E. F; SCOTT, P. Atividade discursiva nas salas de aula de ciências: uma ferramenta sociocultural para analisar e planejar o ensino. Investigações em Ensino de Ciências, v.7, n.3, p.283-306, 2002. 
DOI: $10.12957 / \mathrm{e}-\mathrm{mosaicos} .2020 .46913$

MOZZATO, R. A.; GRZYBOVSKI, D. Análise de Conteúdo como Técnica de Análise de Dados Qualitativos no Campo da Administração: Potencial e Desafios. Revista de Administração Contemporânea, v. 15, n. 4, p. 731-747, 2011.

MUENCHEN, C.; DELIZOICOV, D. Os três momentos pedagógicos e o contexto de produção do livro "Física". Ciência \& Educação, v.20, n.3, p. 617-638, 2014.

NAPPA, N.; INSAUSTI, M. J.; SIGÜENZA, A. F. Obstáculos para generar representaciones mentales adecuadas sobre la disolución. Revista Eureka sobre Enseñanza y Divulgación de las Ciencias, v. 2, n. 3, p. 344-363, 2005.

RIBAS, J. F.; BROIETTI, F. C. D.; LEAL, L. P. V.; PASSOS, M. M. Soluções saturada, insaturada e supersaturada e suas representações por licenciandos em Química. ACTIO - Docência em Ciências, v. 2, n. 2, p. 61-79, 2017.

SILVA, R. M. G.; SCHNETZLER, R. P. Concepções e ações de formadores de professores de Química sobre o estágio supervisionado: propostas brasileiras e portuguesas. Química Nova, v. 31, n. 8, p. 2174-2183, 2008.

VYGOTSKY, L.S. Aprendizado e Desenvolvimento. Um processo sócio-histórico. São Paulo: Scipione, 1993.

Recebido em 27 de novembro de 2019

Aceito em 05 de abril de 2020

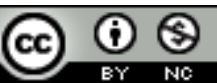

A e-Mosaicos Revista Multidisciplinar de Ensino, Pesquisa, Extensão e Cultura do Instituto de Aplicação Fernando Rodrigues da Silveira (CAp-UERJ) está disponibilizada sob uma Licença Creative Commons - Atribuição-NãoComercial 4.0 Internacional.

Os direitos autorais de todos os trabalhos publicados na revista pertencem ao(s) seu(s) autor(es) e coautor(es), com o direito de primeira publicação cedido à e-Mosaicos.

Os artigos publicados são de acesso público, de uso gratuito, com atribuição de autoria obrigatória, para aplicações de finalidade educacional e não-comercial, de acordo com o modelo de licenciamento Creative Commons adotado pela revista. 